\title{
Leadership Skills of Tuskegee University's Forestry/Natural Resources Management Graduates
}

\author{
Jerry L. Bettis, Sr. \\ Assistant Professor/Extension Specialist \\ Virginia State University, Virginia State University, VA 23806. \\ David Nii 0. Tackie \\ Professor, \\ Tuskegee University, Tuskegee, AL. \\ Jerry L. Bettis, Jr. \\ Ph.D. Scholar, Raleigh, NC.
}

\begin{abstract}
This study focused on Tuskegee University forestry/natural resources management graduates' perspectives about leadership skills possessed. Objectives were to: describe Tuskegee University graduates' participation in high school-, college-, and communitybased leadership development activities; describe how the graduates perceived their leadership skills; identify what variables could be used to explain variance in the overall mean scores of the leadership skills constructs; identify what activities and/or demographic characteristics could be used to explain variance in the perceived leadership skills of the graduates; and obtain preliminary data that provided insight and could inform the professions of the level of leadership skills held by some forestry/natural resources management graduates. Data collection occurred via simple random sampling and a survey. Data analyses occurred via descriptive statistics. Study population consisted of all of Tuskegee University forestry/natural resources management graduates, to include those employed in or seeking employment in the forestry/natural resources management professions. It included those who graduated from Tuskegee University and those who completed a two- or three-year program, transferred, and graduated from partner universities. Graduates of TU's forestry/natural resources management programs agree that they possess leadership skills. Most of the respondents reported that they believed that "participation in college extracurricular activities directly affected my leadership skills." Majority of the respondents indicated that they believed that "participation in college curriculum courses directly affected my leadership skills."
\end{abstract}

Keywords: forestry, humanities, leadership, leadership development, natural resources management, social sciences, survey

\section{INTRODUCTION}

About thirty years ago, leadership skills development became an objective of U.S. land grant undergraduate agriculture (Love and Yoder, 1989) and agriculture-related programs. Today, many institutions of higher education include student leadership skills development in their mission statements (Astin and Astin, 2000). This has led many degree programs, departments, and universities to offer various sets of leadership skills development activities. Leadership skills development activities ranged from formal classes in the curriculum to participation in departmental clubs, student organizations, and student activities. 
For this paper, we will use the following definitions of leadership and development after Bettis et al. (2015): 1) leadership is defined as people working in a given situation (Pearce and Conger, 2003); interactions or relationships among individuals (Kouzes and Posner, 2008); a focus on the needs of the group (Greenleaf, 1977) and the result is an achieved goal; and 2) development is defined "as the evolution of skills (defined broadly to include abilities, capacities, ways of understanding) over time, where early level skills are reorganized into higher-level skills that allow individuals to manage more complex units of information, perspectives, and tasks" (King 2009, p. 598).

We infer from research (Vonhof, 2007, 2008, 2010) that many forestry/natural resources management programs have resorted to a more laissez faire posture instead of formal programs, which include taking a sufficient number of classes in the humanities and social sciences, and especially leadership skills development. These programs encourage students to develop leadership skills by participating in departmental clubs, student organizations, and student activities.

However, Vonhof $(2007,2008,2010)$ stated that forestry/natural resources management students are not prepared to solve the complex social problems they encounter, especially as neophyte resource managers. Vonhof's research suggested that forestry/natural resources management graduates were trained well in the biophysical dimensions but seem to be deficient in the humanities and social sciences as they relate to natural resources management. Since the inception of professional forestry/natural resources management education in the U.S.A., many have argued that humanities and social sciences were necessary as much as biophysical and/or technical competences (Roth, 1910; Toumey, 1922). For instance, in 1963, Dana and Johnson noted that humanities and social sciences received comparatively less emphasis than the technical competences necessary to become a holistic forester or a natural resources manager. More recently, Luloff (1995) and Egan (1996) purported that forestry/natural resources management education failed to provide students with a good perspective of the relationships between society and the natural resources they manage.

Competences in humanities and social sciences (communication, conflict resolution, interpersonal skills, leadership ability, etc.) set forestry/natural resources management managers apart within an organization and lead to leadership positions above the "first line of supervision" in industry and government. There is little to no studies addressing the question of "what are the leadership skills held by forestry/natural resources management students or graduates?" The research questions were: (1) as the student's level of organizationparticipation increases, the opportunity and motivation for developing leadership skills will also increase; and (2) there is no difference in the perceptions of leadership skills held by Tuskegee University's (TU) male and female forestry/natural resources management graduates.

Therefore, we sought to generate information about the leadership skills held by TU's forestry/natural resources management graduates. Objectives were to: (1) describe Tuskegee University forestry/natural resources management graduates' participation in high school-, college-, and community-based leadership development activities; (2) describe how TU graduates' perceived their leadership skills; (3) identify what variables could be used to explain variance in the overall mean scores of the leadership skills constructs; (4) identify what activities and/or demographic characteristics could be used to explain variance in the perceived leadership skills of TU's forestry/natural resources management graduates; (5) describe how males and females differed regarding leadership skills held; and (6) obtain 
preliminary data that provided insight and could inform the professions of the level of leadership skills held by some forestry/natural resources management graduates.

\section{Data collection}

\section{METHODS}

Data collection occurred via a survey instrument. Constructs II - VI were adapted from Birkenholz and Schumacher (1994). The survey instrument included six constructs and consisted of 85 variables. Most of the variables were of the Likert-type scale format. Construct I focused on general background/demographics (e.g., organizations you were a member of while in high school, organizations you were a member of while in college, and non-high school and non-college sponsored organizations you were a member of while in high school and college, and general background), construct II covered administration, and construct III consisted of achievements, construct IV focused on community involvement, construct V covered empathy, and construct VI consisted of problem-solving.

Content and face validity of the instrument occurred via a panel of experts and a survey test of ten graduates. No revisions were necessary following the pilot test and the test surveys were not included in this analysis. The population size for this study included forty-one graduates of TU's forestry/natural resources management programs. The target population included those who graduated from TU and those who completed a two- or three-year program at TU, transferred, and graduated from partner universities. We used a table after Krejcie and Morgan (1970) to determine sample size, $n$. The authors distributed thirty-seven surveys, using simple random sampling, to a subset of TU's forestry/natural resources management graduates. A mailing of survey instruments occurred, following Dillman et al. (2009), on 13 April 2015. The subjects' instructions were to complete the survey independently and return it. Respondents returned fifteen surveys, yielding a response rate of $41 \%$.

\section{Data analysis}

Analyses of data occurred via SAS (1999-2001) and descriptive statistics (means, standard deviations (S.D.), and frequencies). Correlation analyses examined the relationships between the overall mean rating of the leadership skills constructs and selected demographic variables. Spearman Rank analyses examined the relationships between activities participated in high school, college, and other organizations (demographic characteristics) and the leadership skills constructs. Furthermore, the t-test measured the difference of each leadership skills variable's mean score by gender. Following each solicitation, we kept the returned questionnaires separately to analyze via t-test to see if there was a difference between the early and late respondents' responses. This controlled for non-response error. Cronbach's alpha coefficient of reliability for constructs II - VI combined was 0.89 ; construct II was 0.78 ; construct III was 0.80 ; construct IV was 0.67 ; construct V was 0.65 ; and construct VI was 0.75 . An "omitted question," "no answer," "no opinion," or "not applicable" was coded as a 10 and considered a missing case of the unanswered question only. Categorical analysis of means for constructs II VI occurred using the following scale: (1) strongly disagree $(\underline{M}=1.00-1.83)$; (2) moderately disagree $(\underline{M}=1.84-2.67)$; (3) slightly disagree $(\underline{M}=2.68-3.51)$; (4) slightly agree $(\underline{M}=3.52$ 4.35); (5) moderately agree $(\underline{M}=4.36-5.19)$; (6) strongly agree $(\underline{M}=5.20-6.0)$. We evaluated the levels of significance using the following criteria: (1) administration's t-value is significant at the 0.00035 level, based upon Bonferroni's correction 0.05/14; achievement's t-value is significant at the 0.0055 level, based upon Bonferroni's correction $0.05 / 9$; (3) community involvement's t-value is significant at the 0.0083 level, based upon Bonferroni's correction 0.05/6; (4) empathy's t-value is significant at the 0.0071 level, based upon Bonferroni's correction 0.05/7; and (5) problem-solving's t-value is significant at the 0.0071 level, based upon Bonferroni's correction 0.05/7. 


\section{RESULTS}

Because the respondents returned only fifteen surveys, we did not test for non-response error (Lindner et al., 2001). Thus, one should generalize these statistics only to the Tuskegee University forestry/natural resources management populations.

The population size is too small to sample a cohort group separately. Thus, we combined all graduating classes into one population in this study. The respondents' reported gender was $67 \%$ male and 33\% female. Reported mean age was 46.3 years old, $n=15$, and S.D. $=14.85$. The mean number of years employed was $18.2, \mathrm{n}=12$, and S.D. $=16.38$. Most of the subjects, $64 \%$, indicated that they held a leadership position in an organization while in high school. The respondents, 27\%, reported that they held a leadership position in a church's youth organization while in college. When asked, "did you hold a leadership position in a college sponsored organization?" 36\% indicated "yes." The subjects, 36\%, reported that they held a leadership position in a student organization while in college. The majority of the respondents, $73 \%$, responded that they held a leadership position in a professional organization other than their employer.

Most, 79\%, of the respondents reported that they believed that "participation in college extracurricular activities directly affected my leadership skills." The majority of the respondents, $86 \%$, indicated that they believed that "participation in college curriculum courses directly affected my leadership skills." The subjects, 86\%, reported "yes, I am satisfied that my instruction in my forestry/natural resources management department contributed sufficiently to the development of my leadership skills." When asked, "what do you credit with helping you develop your leadership skills?" 73\% indicated required classes, 67\% reported college extracurricular activities, $60 \%$ each indicated free elected classes in college and church/community organizations, and $20 \%$ indicated other. This variable was a check all that apply.

The t-test measured the difference between the male and female respondents' variables' mean scores. Not one variable of the five constructs produced a significantly different t-value. The overall mean score and S.D. for all constructs combined were $\underline{M}=5.32$ and S.D. $=0.26$. Administration construct $\underline{\mathrm{M}}$ and S.D. for males were 5.04 and 0.81 , and for females were 5.05 and 0.98. The $\underline{\mathrm{M}}$ and S.D. for achievement construct for males were 5.53 and 0.79 , and for females were 5.56 and 0.69 . Community involvement construct $\underline{\mathrm{M}}$ and S.D. for males were 5.21 and 0.89 , and for females were 4.50 and 1.77. The $\underline{M}$ and S.D. for empathy construct for males were 5.54 and 0.64 , and for females were 5.57 and 0.96. Problem-solving construct $\underline{\mathrm{M}}$ and S.D. for males were 5.46 and 0.82 , and for females were 5.86 and 0.59 .

Pearson correlation analyses tested for trends in the data for the administration, achievement, community involvement, empathy, and problem-solving leadership skills constructs with selected demographic variables. We used the descriptions outlined by Hopkins (2000) to interpret the correlation coefficients. Here we discuss only statistically significant, moderate associations, $\mathrm{r}>0.30$. ${ }^{*}$ Correlation is significant at the alpha $=0.05$ level and ${ }^{* *}$ correlation is significant at the alpha $=0.01$ level. Cause and effect analyses are beyond the scope of this paper. Empathy and problem-solving leadership skills constructs showed a high significant relationship, $r=0.58^{*}$. Administration and problem-solving leadership skills constructs produced a high significant relationship, $r=0.53^{*}$. A high significant, negative, relationship, $r=$ -0.53*, occurred with the problem-solving leadership skills construct and college organizations membership activity. Furthermore, achievement and problem-solving leadership skills constructs produced a high significant relationship, $r=0.63^{* *}$. A high significant relationship, $r$ 
$=0.64^{* *}$, resulted with administration and community involvement leadership skills constructs.

Spearman Rank correlation coefficients tested the relationships between high school membership, college membership, and non-high school and non-college sponsored organizations activity participation, and the five leadership skills constructs. A significant correlation, $\mathrm{r}_{\mathrm{s}}=0.54^{*}$, resulted with the athletics, the high school membership activity, and the achievement leadership skills construct. Professional/honorary, the college membership activity, and the problem-solving leadership skills construct produced a significant, negative, correlation, $r_{s}=-0.63^{* *}$. A significant, negative, correlation, $r_{s}=-0.50 *$, resulted with intramurals, the college membership activity, and the problem-solving leadership skills construct. Four-H, the non-high school and non-college sponsored organization membership activity, and the problem-solving leadership skills construct showed a significant, negative, correlation, $r_{s}=-0.58 *$. No activities produced a significant correlation with the administration, community involvement, and empathy leadership skills constructs.

\section{DISCUSSION}

Most of the respondents reported that they believed that "participation in college extracurricular activities directly affected my leadership skills." The majority of the respondents indicated that they believed that "participation in college curriculum courses directly affected my leadership skills." When asked, "what do you credit with helping you develop your leadership skills?" the respondents reported "required classes and church/community organizations."

The above statements support the work of Garcia et al. (2017), Keselman et al. (2015), Kodama and Dugan (2013), Dugan and Komives (2010), Massoni (2011), Lawhorn (2008-2009), Cress et al. (2001), and Kezar and Moriarty (2000) as they stated that participants' leadership skills development grew in civic responsibility, leadership skills, multiculturalism awareness, understanding leadership theories, personal, societal values, etc. The above authors' findings support the Pearson correlation analyses.

The Pearson correlation analyses produced five significant relationships with the five leadership skills constructs and selected demographic variables. The problem-solving skills construct showed four significant relationships with administration, achievement, community involvement, and empathy leadership skills constructs. Only one significant relationship resulted from the administration and community involvement leadership skills constructs. The other relationships did not contribute significantly to the leadership skills development involving the five leadership skills constructs and demographic variables.

The Spearman Rank correlation showed that participation in athletics, high school membership activity, and the achievement leadership skills construct produced a significant coefficient. Intramurals and professional/honorary participation were the college membership activities and the problem-solving leadership skills construct that showed significant coefficients. Lastly, 4-H was the non-high school and non-college sponsored organization membership activity, and the problem-solving leadership skills construct that produced a significant coefficient.

The above Pearson correlation and Spearman Rank findings support the work of Garcia et al. (2017), Keselman et al. (2015), Kodama and Dugan (2013), Bloomfield and Barber (2011), Guardia and Evans (2008), Fredricks and Eccles (2006), and Komives et al. (2005) in that participation in leadership skills development assisted in students' engagement, self-concept, 
academic achievement, self-worth, social and academic self-concept. All led to increased leadership skills development. Serving in extracurricular organizations led to increased leadership skills development (Garcia et al., 2017, Martinelli and Erzikova, 2017, Moreno and Sanchez Banuelos, 2013, Dugan and Komives, 2010, Ewing et al., 2009, and Rubin et al., 2002).

\section{CONCLUSIONS}

Graduates of TU's forestry/natural resources management programs agree that they possess leadership skills. The graduates' participation in high school and college student activities resulted in leadership skills development. Participation in professional/honorary, intramurals, athletics, and 4-H organizations in high school and college led to leadership skills development. The five leadership skills constructs all produced variables that positively related to the constructs' overall mean scores. Participation in intramurals and 4- $\mathrm{H}$ were the only variables that showed negative relationships with the perceived leadership skills. However, a number of high school and college activities influenced TU graduates' perceived leadership skills.

\section{RECOMMENDATIONS}

Based upon the results of this study, the authors recommend that Tuskegee University forestry/natural resources management programs' leaders should consider: (1) encouraging high school and college students to participate in extracurricular activities, clubs, and organizations as they lead to developing leadership skills; (2) advising forestry/natural resources management students to enroll in leadership skills development courses and programs offered at their partner universities; and (3) developing strategies which will develop leaders who are able to recognize changes in the forestry/natural resources management industries and can guide and direct the industries into the future.

\section{STUDY LIMINTATIONS}

Because of the limited number of participant responses, the following biases may influence these results: (1) unit non-response bias; (2) self-selection bias; (3) sampling bias; and (4) under-coverage bias resulting from self-selection. Because of the limited number of female unit responses and the apparent unit non-response bias, one should generalize the survey results with caution.

\section{References}

Astin, A. W. and A. W. Astin. 2000. Leadership reconsidered. Engaging higher education in social change. Battle Creek, MI: W. K. Kellogg Foundation.

Bettis, Sr. J. L., C. S. Christian and B.M. Allen. 2015. Forestry Students' perspectives about participation in leadership development. North American Colleges and Teachers of Agriculture Journal, December 2015. 300305 pp.

Bloomfield, C. J. and B. L. Barber. 2011. Developmental experiences during extracurricular activities and Australian adolescents' self-concept: Particularly important for youth from disadvantage school. J. Youth and Adolescence, 40:582-594.

Birkenholz, R. J. and L. G. Schumacher. 1994. Leadership Skills of College of Agriculture Graduates. J. Agri. Education, 35(4):1-8.

Cress, C. M., H. S. Astin, K. Zimmerman-Oster and J. C. Burkhardt. 2001. Development outcomes of college students' involvement in leadership activities. J. College Student Development, 42:15-27.

Dana, S. T. and E. W. Johnson. 1963. Forestry education in America: today and tomorrow. Society of American Foresters, Wash, DC. 402 p.

Dillman, D. A., J. D. Smyth and L. M. Christian. 2009. Internet, mail, and mixed-mode surveys: The tailored design method. John Wiley \& Sons, $3^{\text {rd }}$ edition. Hoboken, New Jersey.

Dugan, J. P. and S. R. Komives. 2010. Influences on college students' capacities for socially responsible leadership. J. College Student Development, 51, 525-549. doi:10.1353/csd.2010.0009 
Egan, A. F. 1996. "Snappin" them red suspenders: Introducing forestry students to the rest of society. J. For. 94(3):9-13.

Ewing, J. C., J. A. Bruce and K. G. Ricketts. 2009. Effective leadership development for undergraduates: How important is active participation in collegiate organizations? J. Leadership Education, 7:118-131.

Fredricks, J. and J. Eccles. 2006. Extracurricular involvement and adolescent adjustment: Impact of duration, number of activities, and breadth of participation. Applied Developmental Science, 10:136-146.

Garcia, G. A., A. H. Huerta, J. J. Ramirez and O. E. Patron. 2017. Contexts that matter to the leadership development of Latino Male college students: a mixed methods perspective. J. College Student Development 58(1) pp. 1-18, January.

Greenleaf, R. K. 1977. Servant Leadership. New York. Paulist Press.

Guardia, J. R. and N. J. Evans. 2008. Factors influencing the ethnic identity development of Latino fraternity members at a Hispanic Serving Institution. J. College Student Development, 49, 163-181.

Hopkins, W. G. 2000. A new view of statistics. Internet Society for Sport Science. Available at http://www.sportsci.org/resource/stats. (Accessed Mar. 7, 2011).

Keselman, A. E., A. Ahmed, D. C. Williamson, J. E. Kelly and G. A. Dutcher. 2015. Harnessing health information to foster disadvantaged teens' community engagement, leadership skills, and career plans: a qualitative evaluation of the Teen Health Leadership Program. J. Medical Library Association, 103(2):83-86.

Kezar, A. and D. Moriarty. 2000. Expanding our understanding of student leadership development: A study exploring gender and ethnic identity. J. Collee Student Development, 41, pp. 55-69.

King, P. M. 2009. Principles of development and developmental change underlying theories of cognitive and moral development. J. College Student Development 50(6):597-620.

Kodama, C. M. and J. P. Dugan. 2013. Leveraging leadership efficacy for college students: Disaggregating data to examine unique predictors by race. Equity and Excellence in Education, 46, 184-201.

doi:10.1080/10665684.2013.780646

Komives, S. R., J. E., Owen, S. D. Longerbeam, F. C. Mainella and L. Osteen. 2005. Developing a leadership identity: A grounded theory. J. College Student Development, 46, 593-611.

Kouzes, J. and B. Posner. 2008. The student leadership challenge: five practices for exemplary leaders. San Francisco: Jossey-Bass.

Krejcie, R. V. and D. W. Morgan. 1970. Determining sample size for research activities. Educational and Psychological measurement, 30(3):607-610.

Lawhorn, B. 2008-2009. Extracurricular activities: the afterschool connection. Occupational Outlook Quarterly winter 2008-2009. Available at www.bls.gov/opub/ooq/2008/winter/art02.pdf; last accessed Apr. 4, 2014.

Lindner, J. R., T. H. Murphy and G. E. Briers. 2001. Handling nonresponse in social science research. J. Agri. Ed. 42(4):43-53.

Love, G. M. and E. P. Yoder. June 1989. An assessment of undergraduate education in American colleges of agriculture. State College, PA. Pennsylvania State University, College of Agriculture.

Luloff, A. E. 1995. Regaining vitality in the forestry profession: a sociologist's perspective. J. For. 93(11):6-9.

Martinelli, D and E. Erzikova. 2017. Public relations leadership development cycle: a cross-cultural perspective. Public Relations Review, 43:1062-1072.

Massoni, E. 2011. Positive effects of extracurricular activities on students. ESSAI, vol. 9, article 27. Available at http://dc.cod.edu/ essai/ vol9/ iss1/27; last accessed Apr. 4, 2014.

Moreno, D. R. and S. M. Sanchez Banuelos. 2013. The influence of Latina/o Greek sorority and Fraternity involvement on Latina/o college student transition and success. J. Latino/Latin American Studies, 5(2), 113-125.

Pearce, C. L. and J. A. Conger. 2003. Shared leadership: reframing the hows and whys of leadership. Thousand Oaks, Ca: Sage Publications.

Roth, F. 1910. The curriculum in forestry education. J. For. 8(1):17-25.

Rubin, R. S., W. H. Bommer and T. T. Baldwin. 2002. Using extracurricular activity as an indicator of interpersonal skill: Prudent evaluation of recruiting malpractice? Human Resource Management, 41:441-454.

SAS Institute Inc. 1999-2001. SAS?STAT software. SAS system for Windows V8, Cary, NC, USA. 
Bettis, J. L. Sr., Tackie, D. N. O., \& Bettis, J. L. Jr. (2020). Leadership Skills of Tuskegee University's Forestry/Natural Resources Management Graduates. Advances in Social Sciences Research Journal, 7(2) 229-236.

Toumey, J. W. 1922. Opening address, P. 4-6 in Education of Forestry: Proceedings of the second national conference. USID, Bureau of Education Bulletin, 1921, NO 44, 70 p.

Vonhof, S. 2010. Deficiencies of undergraduate forestry curricula in their humanities and social sciences requirements. J. For. 108(8):413-418.

Vonhof, S. 2008. Out standing in left field: disciplinary boundaries and undergraduate natural resources education. Available online at ir.library.oregonsate.edu/jspui/handle/1957/7138; last accessed July 2010.

Vonhof, S. 2007. The "soft" side of forestry: how accredited undergraduate forestry curricula address the humanities and social sciences. In Proc. Society of American Foresters 2007 National Convention. Portland, OR. October 23-27. 